\title{
Um estudo sobre a produção de clichês tipográficos com a tecnologia de corte à laser
}

A study about the production of typographic clichés with laser cutting technology

\author{
Filipe Aca, Isabella Ribeiro Aragão, Raquel Alcantara \& Silvio Barreto Campello
}

clichês, corte à laser, tipografia, O Gráfico Amador

\begin{abstract}
A produção de clichês tipográficos vêm se tornando rara, em contrapartida, jovens impressores estão se apropriando da impressão tipográfica nos últimos anos. Este artigo relata uma pesquisa sobre a produção de clichês tipográficos cortados à laser como forma de testar novas tecnologias na fabricação e utilização de materiais tipográficos. Para isso, diferentes materiais (MDF, acrílico e linóleo) foram cortados, e montados em uma base de madeira. Com intuito de avaliar os diferentes materiais, imprimimos uma tiragem de 1000 folhas de papel na impressora tipográfica. Os resultados indicam a possibilidade de uso dos três tipos de clichês, com qualidade de impressão semelhantes. No entanto, a escolha do material mais adequado a cada projeto pode levar em consideração critérios como disponibilidade e preço do material, preço e características na fase do corte, além de ajustes durante a impressão.
\end{abstract}

\section{typographic cliché, laser cut, typography, O Gráfico Amador}

The production of typographic clichés has become rare while young printers are becoming more familiar with typographic techniques in the latest years. This paper reports a research on the production of laser cut typographic clichés as a way to test new technologies in the production and use of typographic materials. For this, different materials (MDF, acrylic and linoleum) were cut, and assembled on a wooden base. In order to evaluate the different materials, a print run of 1000 sheets of paper were printed on the printing press. The results indicate the possibility of use of the three types of clichés with similar print quality. However, choosing the most appropriate material for each project may take into account criteria such as availability and price of the material, price and characteristics at the cutting stage, and adjustments during printing.

\section{Introdução}

Desde o final do século passado o interesse pelo processo de impressão tipográfico cresce no Brasil e no mundo por designers que a utilizam como diferencial em seus projetos (Neder, 2014). As jovens oficinas que imprimem com letterpress, nome utilizado local e internacionalmente, utilizam uma placa de fotopolímero ou zinco que engloba toda a arte final, seja ela pictórica e/ou verbal. Em contrapartida, a quantidade de empresas que produzem tipos e clichês estão diminuindo cada vez mais. Neste contexto, buscar outras alternativas pode ser uma solução interessante para imprimir clichês pictóricos em tipografia, por exemplo, recuperar a tradição de matrizes em madeira ou se apropriar de novas tecnologias, como a impressão 3D e corte à laser.

Clichês tipográficos são matrizes de metal com imagem e/ou texto em relevo que podem ser produzidos através da estereotipia, galvanotipia ou fotogravura para serem utilizados na máquina tipográfica (Porta, 1958, p.79). Em geral, essas superfícies gravadas são fixadas em bases de madeira com cola. Nesse contexto, é importante deixar claro que não estamos abarcando os clichês (macho e fêmea) usados na produção de relevo.

Um dos principais expoentes do design gráfico brasileiro que produziu seus impressos com a técnica de composição e impressão tipográfica foi O Gráfico Amador (1954-1961), grupo recifense que teve como fundadores Aloísio Magalhães, Orlando da Costa Ferreira, José Laurenio de Melo e Gastão de Holanda. Observando os projetos e impressos d'O Gráfico, é possível perceber um cuidado e interesse na produção de livros de forma experimental, 'seus

Anais do 9 CIDI e 9 CONGIC

Luciane Maria Fadel, Carla Spinillo, Anderson Horta, Cristina Portugal (orgs.)

Sociedade Brasileira de Design da Informação - SBDI

Belo Horizonte | Brasil | 2019

ISBN 978-85-212-1728-2
Proceedings of the 9th CIDI and 9th CONGIC

Luciane Maria Fadel, Carla Spinillo, Anderson Horta, Cristina Portugal (orgs.)

Sociedade Brasileira de Design da Informação - SBDI Belo Horizonte | Brazil | 2019

ISBN 978-85-212-1728-2 
participantes puseram à prova técnicas e influências ao projetar e imprimir seus livros. Essa característica encontra paralelo em outras áreas da cultura brasileira, em que se pode verificar forte tendência a sintetizar ideias de origens diferentes' (Lima, 2014, p.80).

Eles utilizavam diversas técnicas de impressão, além da tipográfica, como a litografia e xilogravura para a reprodução de imagens. Enquanto a grande maioria dos textos eram compostos com tipos móveis, as formas feitas com clichês foram subvertidas na oficina amadora, já que várias vezes foram produzidos por eles próprios de maneira alternativa.

Este artigo apresenta os resultados de uma pesquisa aprovada pelo Programa Institucional de Bolsas de Iniciação em Desenvolvimento Tecnológico e Inovação (PIBITI) 2018-2019, e realizada por Filipe Aca, no Laboratório de Práticas Gráfica do Departamento de Design da UFPE, com objetivo principal de testar novas tecnologias e materiais na produção de clichês tipográficos.

\section{A tecnologia de corte à laser e materiais}

As novas tecnologias de fabricação digital têm se tornado mais acessíveis, laboratórios de prototipagem e de fabricação digital já são comuns em várias cidades do Brasil e possibilitam o processo de desenvolvimento de produtos e realizações de experimentos de forma rápida e barata (Oliveira, 2016). Dentre as tecnologias disponíveis nos laboratórios, o corte à laser foi a que mais se adequou aos critérios de custo, tempo de produção e acessibilidade aos materiais.

Para esta pesquisa, a primeira atividade analisou os clichês impressos nas publicações guardadas na biblioteca da Fundaj, acervo público do estado de Pernambuco com maior coleção do grupo, com as seguintes etapas: seleção das publicações com clichês de autoria d'O Gráfico Amador; registro e medição das formas impressas; classificação por meio de fichamento de acordo com a técnica de produção da matriz, processo de impressão, quantidade de cores, complexidade do desenho e estilo de ilustração.

Por meio das informações relacionadas com quantidade de cores, complexidade do desenho e estilo de ilustração foi possível identificar quais formas eram mais adequadas para serem vetorizadas. Com a análise dos clichês, ratificamos o estudo de Lima (2014) ao verificar que o grupo produziu uma grande variedade de estilos e técnicas empregadas, desde o clichê em metal, xilogravura, até aqueles produzidos artesanalmente com barbante. Aqueles que se adequaram mais aos requisitos dos arquivos digitais da máquina de corte à laser foram os produzidos em uma cor, sem variação tonal, em linóleo ou estêncil, com simplicidade do desenho ou formas mais geometrizadas e sintéticas, como os apresentados nas figuras 1 . llustrações com muitos detalhes resultariam em imagens vetoriais com pontos e traços muito próximos, dificultando o corte à laser, prejudicando a qualidade final e resistência da peça. 
Figuras 1: Duas xilogravuras ilustradas por Reynaldo Fonseca para o livro Ciclo, de Carlos Drummond de Andrade, e vinhetas em linóleo do livro Dez sonetos sem matéria, de Orlando da Costa Ferreira, respectivamente.

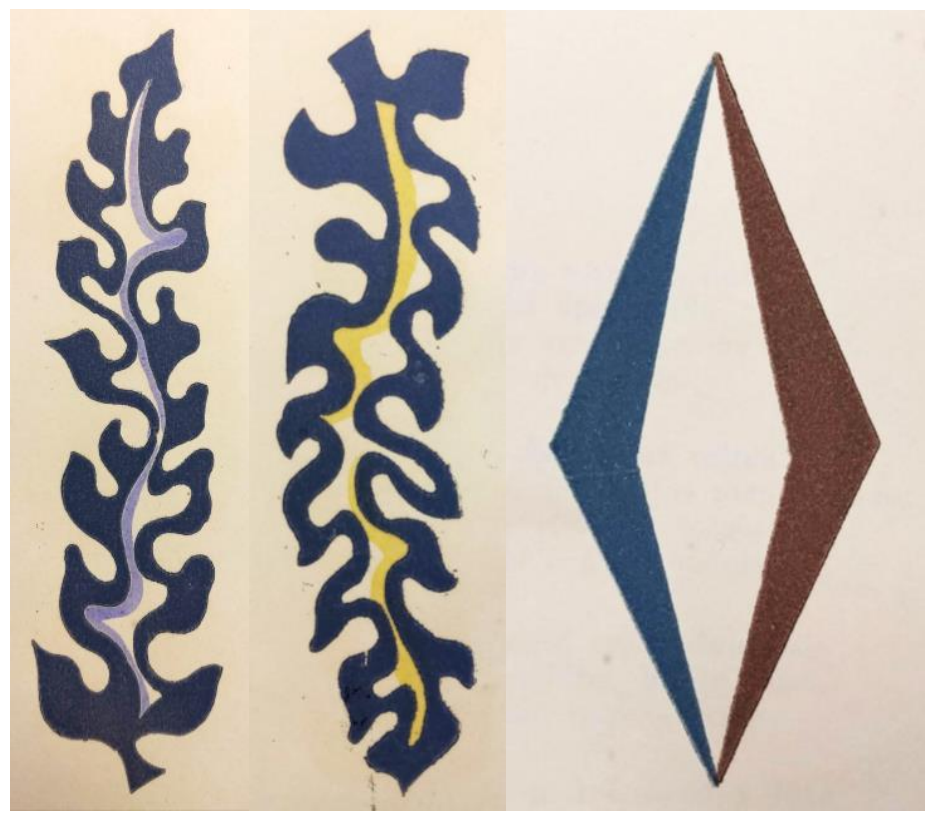

Segundo os manuais de alguns fabricantes, como a Trotec Laser e a Automatisa, a máquina de corte à laser opera com uma grande variedade de materiais, como certos tipos de metal (folhas de alumínio, bronze, cobre, dentre outros), acrílico, borracha, madeira e MDF. Por outro lado, materiais que possuem cloreto de polivinila (PVC), polivinil butiral (PVB),

politetrafluoretileno (PTFE /Teflon) ou materiais contendo halogênios (flúor, cloro, bromo, iodo e ástato), resinas epóxi ou fenólicas, por exemplo, não podem ser cortadas neste tipo de equipamento por conta de gases ou poeiras tóxicas liberadas durante o processo.

Afora os critérios técnicos mencionados acima, também avaliamos a disponibilidade e facilidade de compra dos materiais. Desta forma escolhemos o acrílico e MDF, disponíveis gratuitamente nas caixas de refugo do L.O.U.Co - Laboratório de Objetos Urbanos Conectados, e o linóleo, disponível em nosso laboratório como sobra de material. Todos materiais possuíam aproximadamente $3 \mathrm{~mm}$ de espessura.

Para o teste de impressão era importante que os materiais pudessem ser cortados sem a liberação de gases tóxicos: o acrílico e o MDF são amplamente utilizados nesses tipos de tecnologia, sendo confirmada a segurança pelos operadores e manuais dos fabricantes das máquinas. O linóleo possui composição natural, com farinha de madeira, óleo de linhaça, resina de árvore, pigmentos naturais, juta e cal, sendo assim passível de ser cortado à laser. Em algumas lojas de Recife, o linóleo é comercializado como neolite, que também é um material direcionado para revestimento com características semelhantes.

Além disso, as máquinas dos laboratórios consultados possuem exaustores para melhorar a qualidade do ar dos ambientes. Cada material reage de forma diferente ao feixe do laser, por isso, o resultado final do corte pode variar de acordo com a base utilizada, por exemplo, durante o corte o linóleo apresentou uma liberação de fuligem, sendo necessário limpar o material ao retirar da cortadora. $O$ acrílico adquiriu um contorno fino ao redor das partes cortadas, já o MDF passou a ter uma borda escurecida após o corte.

As máquinas empregadas no corte do acrílico e MDF foi a Trotec speedy 100, do L.O.U.Co, e a Automatisa Dua, do GREA3D, foi usada para cortar o linóleo. As peças cortadas levaram aproximadamente o mesmo tempo para serem produzidas: 21 minutos. A composição digital que foi levada para o corte (figura 2) teve que ser decidida também pelo tamanho da máquina de impressão e disponibilidade do papel, que comentaremos a seguir. Sendo assim, decidimos que ela deveria caber no formato A4. 
Figura 2: Arquivo para corte à laser, espessura do traço de $0,001 \mathrm{~mm}$.

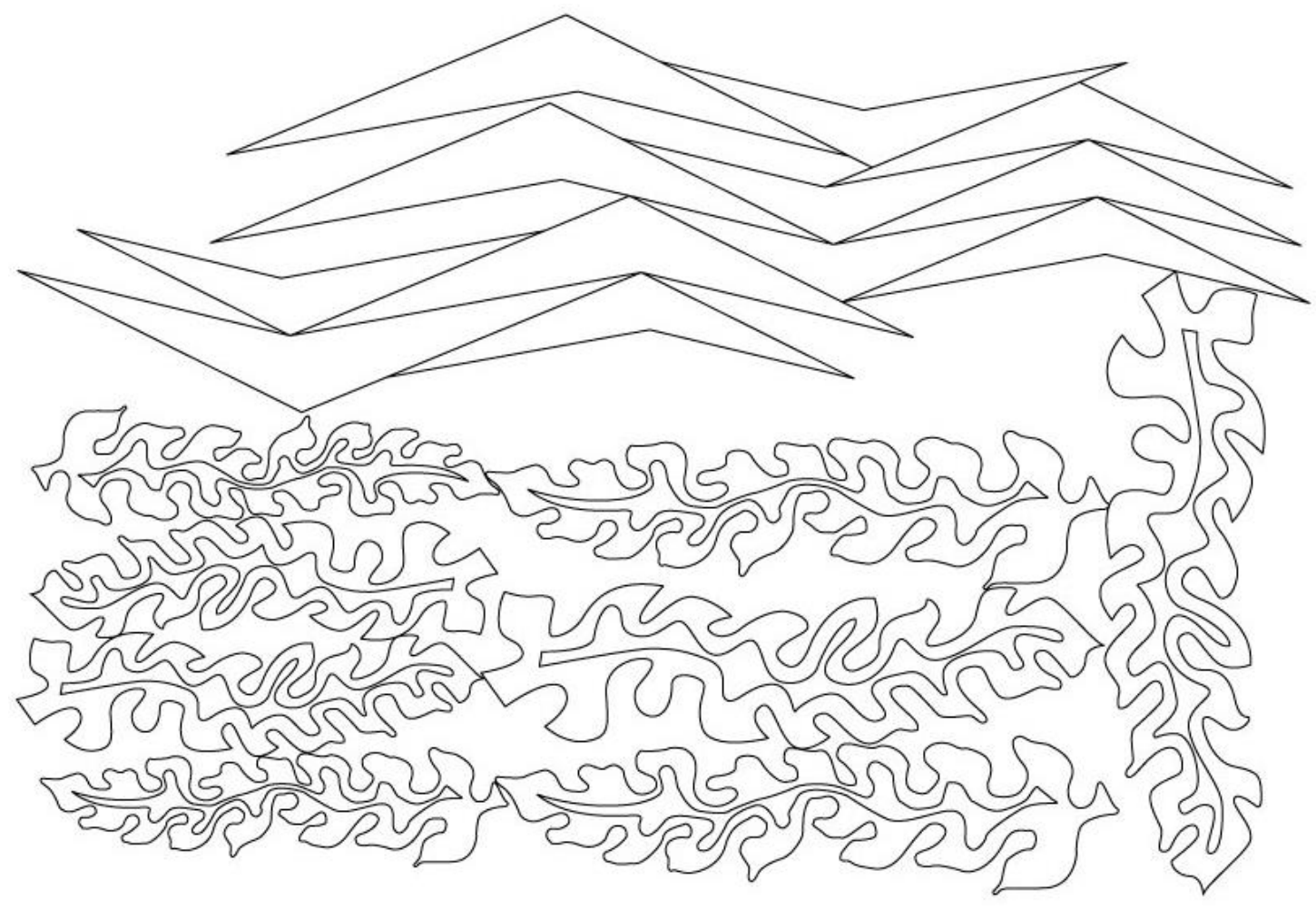

\section{Definição do teste de impressão}

Para que o teste fosse realizado, tornou-se necessário confeccionar os clichês e executar a etapa anterior à impressão: a composição tipográfica.

Para a base dos clichês, um MDF laminado de $18 \mathrm{~mm}$ de espessura foi encomendado a um marceneiro com tamanho tipográfico de 232 pt de largura e 432 pt de altura, facilitando a composição dos clichês com os tipos de metal. Para tanto, levamos um gabarito de papel para o corte ser realizado no tamanho exato.

As peças cortadas foram aplicadas sobre essa base de MDF utilizando a cola universal Pegamil Artesanato e para atingir a altura necessária para a impressão, ainda foi acrescido um suporte de papel paraná de $2 \mathrm{~mm}$, fixado com cola branca. Em relação à composição, precisamos utilizar apenas dois elementos cortados e decidimos inserir junto com os clichês que produzimos tipos móveis de metal da maior fonte do LPG: Grotesca normal meia preta 60 pt, para verificar a relação entre todos os materiais durante o processo, figura 3.

Logo após a etapa de ajustes de pressão, as matrizes de acrílico e linóleo descolaram. Para reuni-las à base foi utilizada uma nova cola, a cola de contato Brascoplast, de acordo com as instruções da embalagem. Outro descolamento aconteceu, desta vez com a matriz de MDF, antes da segunda tiragem. Como já havíamos utilizado duas colas de contato, escolhemos arrumar os clichês de MDF e acrílico com a super cola Three Bond Super 1000.

Todas essas etapas foram executadas pelos autores do artigo. Para as fases posteriores contamos com a colaboração do impressor Maciel Cunha, que trabalha com este equipamento há mais de 40 anos: fechamento da rama (figura 3), ajustes na máquina e impressão. 
Figura 3: A rama com a composição de clichês de acrílico, MDF e linóleo, respectivamente, junto com os tipos de metal abaixo.

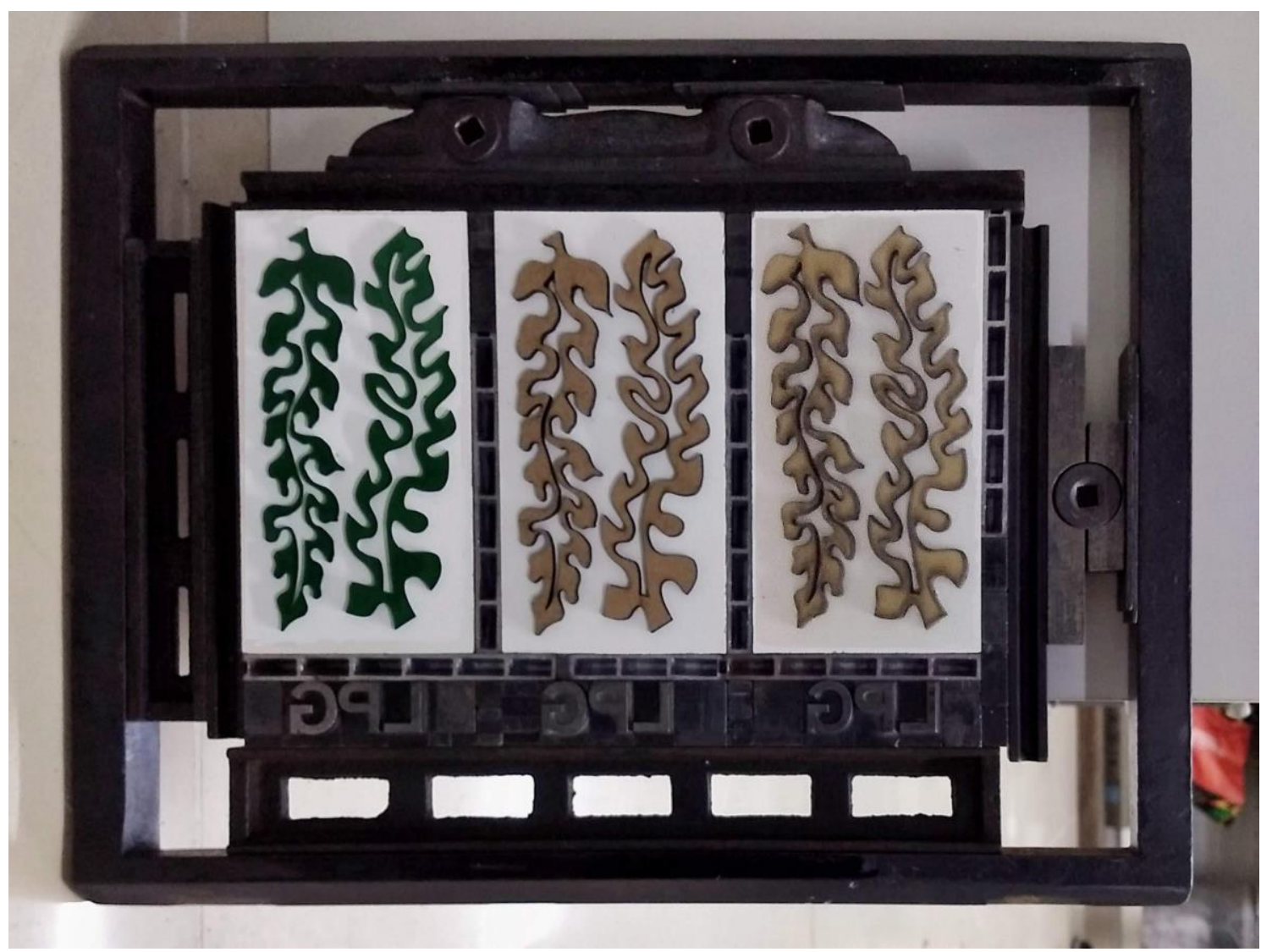

A impressora operada por Maciel é elétrica do tipo Minerva de alimentação manual da marca brasileira $T$. Janer, com formato 8. Como outros trabalhos estavam sendo impressos no LPG, tivemos que adequar a impressão ao cronograma do laboratório. Portanto, a tiragem foi dividida em dois dias: uma resma de 500 folhas de papel sulfite $45 \mathrm{~g} / \mathrm{m}^{2}$, da marca One, foi impressa com a tinta preta para offset da marca Printcor; enquanto a segunda entrada, dois dias depois, foi impressa com a mesma quantidade de papéis na cor magenta para offset, da marca FlintGroup. Para o ajuste da máquina foram usados 19 papéis adicionais no primeiro dia.

\section{Análise das impressões}

Para análise das impressões, dividimos as primeiras 500 impressões em grupos de 50 folhas para serem avaliados e levamos em consideração os seguintes critérios: cobertura, uniformidade, ajuste da máquina e resistência do material.

O linóleo se mostrou estável desde o início, apresentando uma boa cobertura nas 1000 impressões. O acrílico precisou de mais ajustes para aumentar a pressão da máquina, visto que apresentou uma borda nas primeiras impressões (figura 4), para chegar na cobertura desejada. Este material também se mostrou mais suscetível a absorver partículas de poeira e ter sua superfície danificada que podem marcar a impressão no papel. 
Figura 4: Impressão realizada durante os testes de ajuste da máquina, os materiais em cada figura, da esquerda para direita, são: linóleo, MDF e acrílico. Os caracteres são tipos em metal (usado com permissão dos autores do artigo).
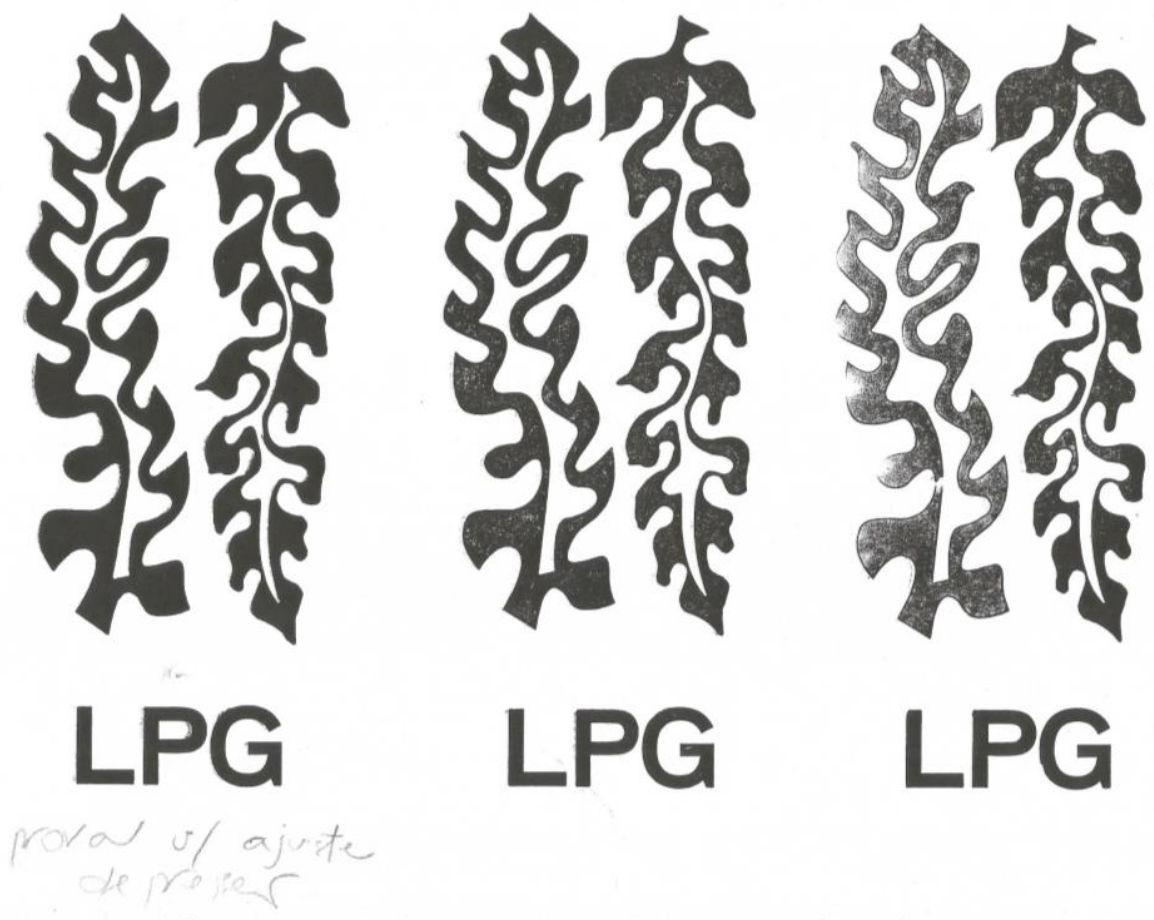

O MDF também necessitou de mais ajustes para chegar a uma boa cobertura, precisando ser entintado algumas vezes pelos rolos para conseguir absorver melhor a tinta. No entanto, depois dos ajustes finalizados não existe uma diferenciação significativa no que concerne a qualidade de impressão dos três materiais testados, conforme podemos perceber nas figuras apresentadas abaixo. Por essa uniformidade na cobertura, não sentimos necessidade de realizar a mesma análise na segunda tiragem. 

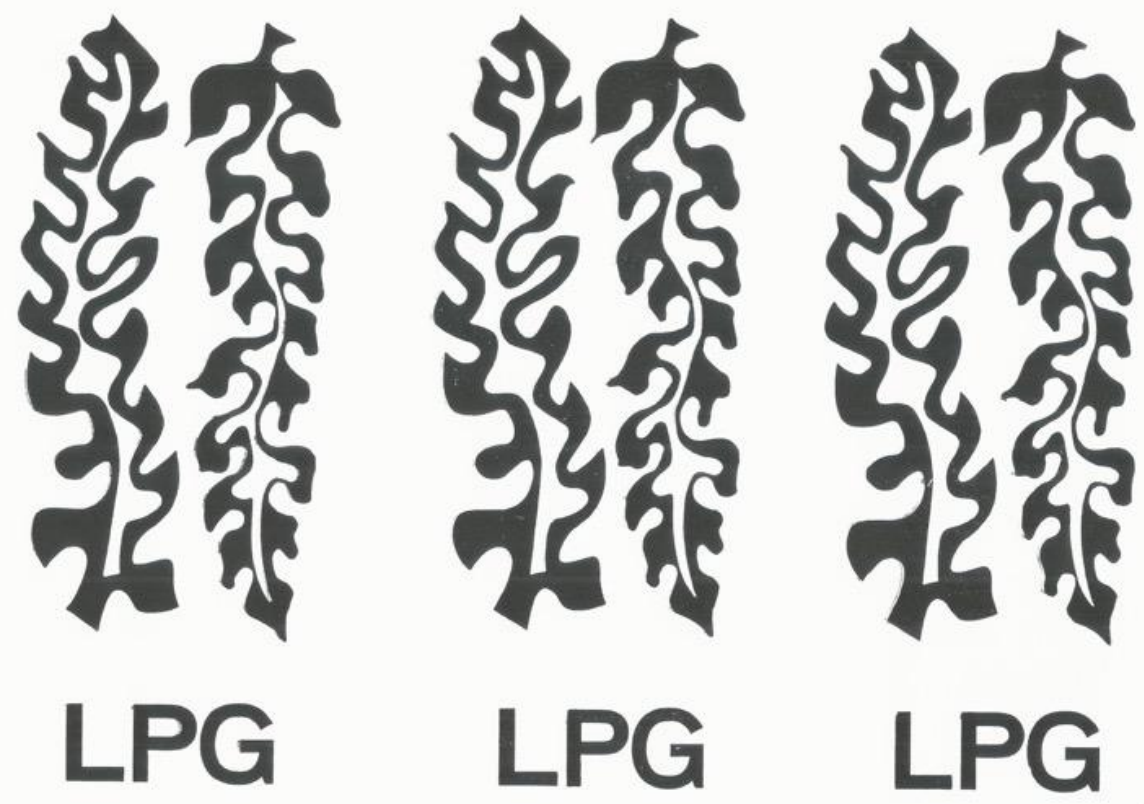

Figura 6: Impressão de número 500.
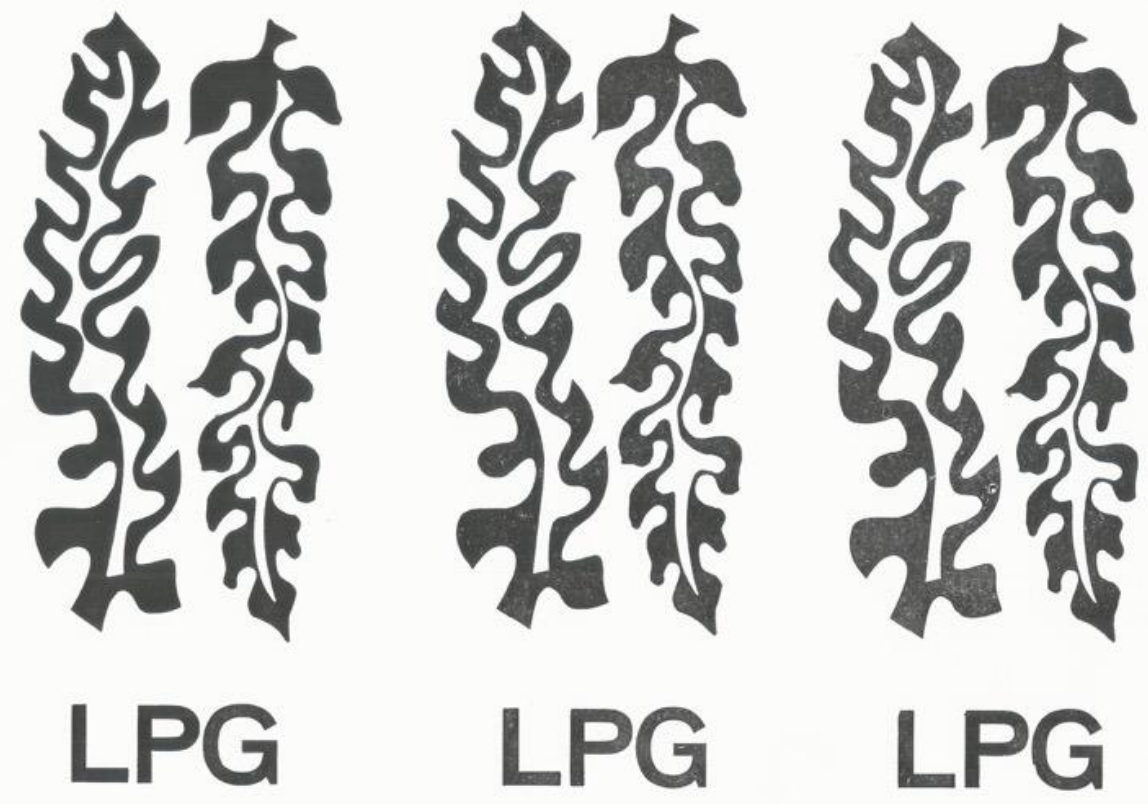

Anais do 9 Congresso Internacional de Design da Informação | CIDI 2019

Proceedings of the 9th Information Design International Conference 
Figura 7: Impressão de número 501.
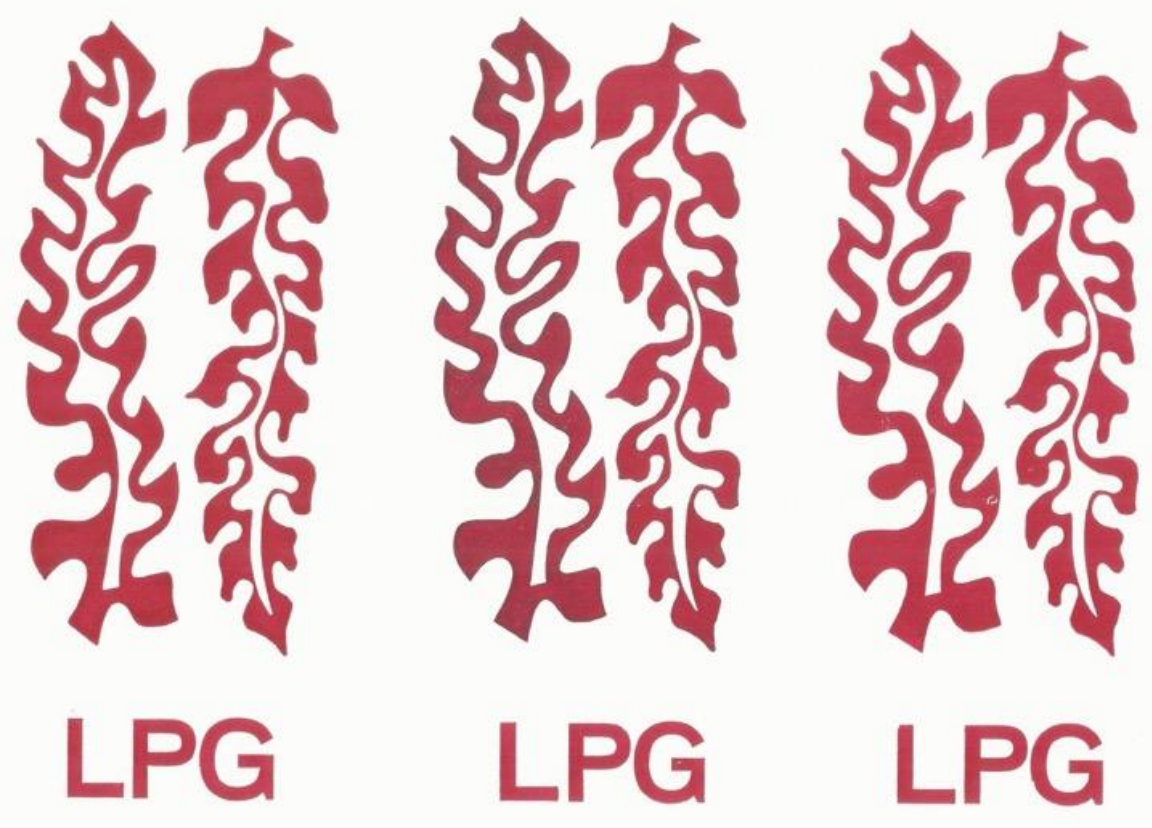

Figura 8: Impressão de número 1000.
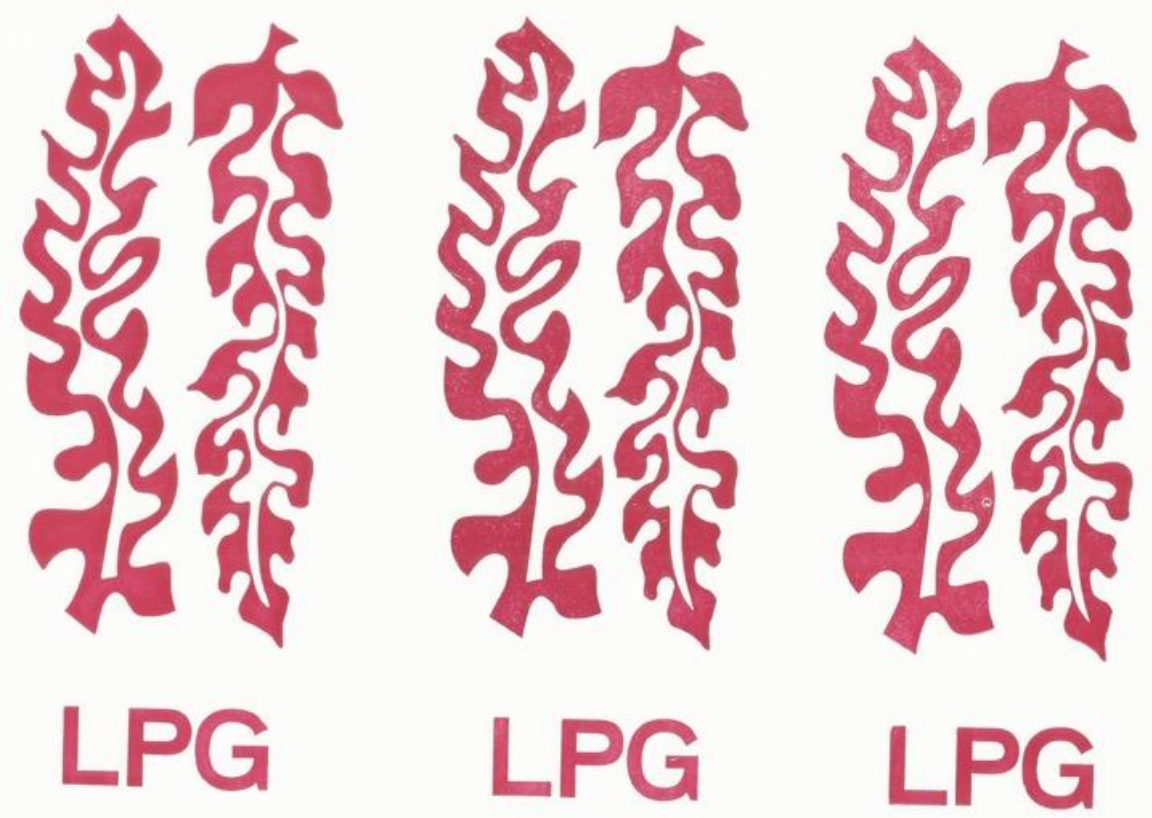

Embora não tenhamos percebido mudanças significativas, o MDF e acrílico são mais propícios a apresentarem pequenas falhas de impressão ao longo da tiragem. No nosso caso,

Anais do 9 Congresso Internacional de Design da Informação | CIDI 2019

Proceedings of the 9th Information Design International Conference 
conseguíamos voltar a qualidade desejada com a liberação de mais tinta na máquina.

É importante mencionar que a impressão tipográfica com tipos móveis depende essencialmente de três fatores: espessura e superfície do papel, qualidade e quantidade de tinta e pressão da máquina. Cabe ao impressor encontrar a regulagem mais adequada ao trabalho impresso. Com os resultados dessa pesquisa, podemos afirmar que o material escolhido para produzir o clichê não aponta grandes diferenças de impressão em relação ao metal dos tipos.

Igualmente podemos concluir que a tecnologia de corte à laser se mostra bastante útil para a produção de clichês tipográficos, pois é de fácil acesso em laboratórios de prototipagem, atualmente comuns em várias cidades do Brasil, além do seu baixo custo. As possibilidades de materiais também são grandes, sendo viável a utilização de outros materiais afora os que foram testados, como o compensado. Após a impressão de 1000 exemplares, quantitativo coerente com as tiragens realizadas atualmente em letterpress, os clichês ainda estão colados e aparentemente aptos a duplicar a tiragem. Não há indício algum de desgaste de material na superfície dos clichês.

Uma das desvantagens da tecnologia testada é a limitação na complexidade dos desenhos a serem cortados. Por conta disso, não seria possível reproduzir um dos clichês à traço utilizado nos livros d'O Gráfico Amador (figura 9) porque a imagem tem linhas muito próximas que seriam reconhecidas como uma linha única.

Figura 9: Clichê em metal presente no livro A tecelã de autoria de Reynaldo Fonseca.

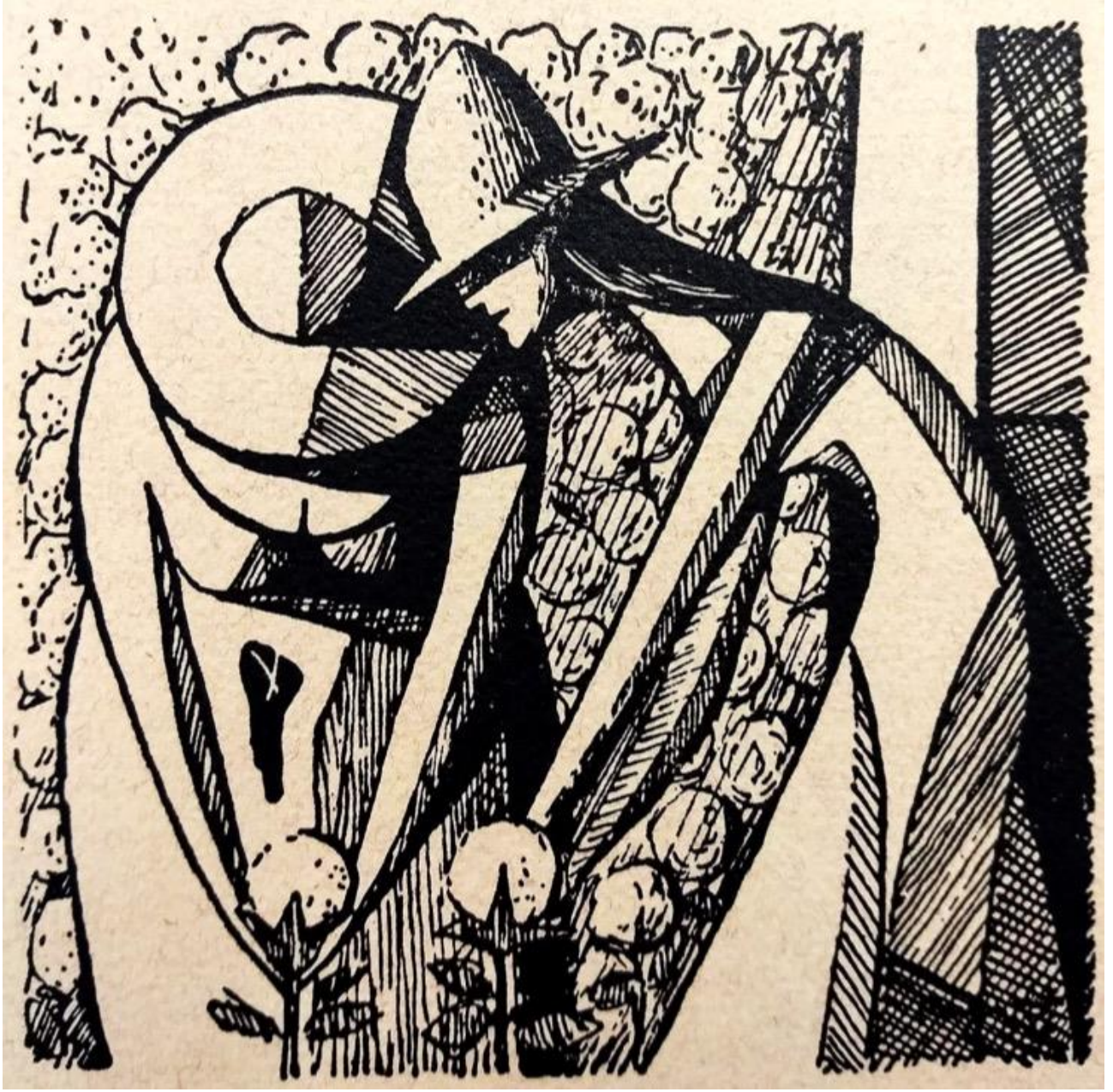

Embora o resultado aponte para uma igualdade no que concerne à qualidade de impressão, outros critérios podem ser levados em consideração na escolha do material da superfície do Anais do 9 Congresso Internacional de Design da Informação | CIDI 2019 Proceedings of the 9th Information Design International Conference Anais do $9^{\circ}$ Congresso Nacional de Iniciação Científica em Design da Informação | CONGIC 2019 Proceedings of the $9^{\text {th }}$ Information Design Student Conference 
clichê: disponibilidade, preço do material, preço do corte, características na fase do corte e comportamento durante a impressão.

Tabela 1: Informações sobre os clichês produzidos no corte à laser em Recife.

\begin{tabular}{l|l|l|l|l} 
Material & Preço & Disponibilidade & Corte & Impressão \\
\hline Acrílico & $\begin{array}{l}\mathrm{R} \$ 30,00 / \text { placa } \\
\text { de } 30 \times 60 \mathrm{~cm}\end{array}$ & $\begin{array}{l}\text { Pode ser } \\
\text { encontrado nos } \\
\text { laboratórios de } \\
\text { prototipagem }\end{array}$ & $\begin{array}{l}\text { Adquiriu uma borda } \\
\text { mais fina em seu } \\
\text { contorno }\end{array}$ & $\begin{array}{l}\text { Apresentou o } \\
\text { contorno da borda } \\
\text { nas impressões de } \\
\text { teste, sendo corrigida } \\
\text { com ajustes de } \\
\text { pressão na máquina }\end{array}$ \\
\hline Linóleo & $\begin{array}{l}\mathrm{R} \$ 63,00 / \text { placa } \\
\text { de } 100 \times 98 \mathrm{~cm}\end{array}$ & $\begin{array}{l}\text { Pode ser } \\
\text { encontrado em } \\
\text { lojas de } \\
\text { revestimento/ } \\
\text { construção }\end{array}$ & $\begin{array}{l}\text { Liberou fuligem e } \\
\text { necessitou de ajustes } \\
\text { na máquina de corte } \\
\text { por não ser um } \\
\text { material disponível no } \\
\text { local }\end{array}$ & $\begin{array}{l}\text { Acomodou } \\
\text { rapidamente a tinta, } \\
\text { chegando ao } \\
\text { resultado desejado } \\
\text { com menos ajustes } \\
\text { na máquina }\end{array}$ \\
\hline MDF & $\begin{array}{l}\mathrm{R} \$ 6,00 / \text { placa de } \\
30 \times 60 \mathrm{~cm}\end{array}$ & $\begin{array}{l}\text { Pode ser } \\
\text { encontrado nos } \\
\text { laboratórios de } \\
\text { prototipagem }\end{array}$ & $\begin{array}{l}\text { Obteve uma borda } \\
\text { escura e liberou } \\
\text { cheiro característico } \\
\text { durante o corte }\end{array}$ & $\begin{array}{l}\text { Primeiros testes de } \\
\text { impressão ficaram } \\
\text { claros, também } \\
\text { necessitando de } \\
\text { ajustes na pressão } \\
\text { da máquina }\end{array}$ \\
\hline
\end{tabular}

Em relação ao valor de corte de cada peça, ele pode ser ainda mais reduzido, levando em consideração que, dependendo do tamanho, é possível garimpar nos laboratórios de prototipagem refugos e sobras de materiais de outros trabalhos, o que geralmente costuma ser gratuito. Além disso, o L.O.U.Co oferece descontos para projetos e pesquisas de fins acadêmicos, assim como o GREA3D. Dessa forma, este tipo de projeto se mostra bastante viável e de baixo custo, respeitando e adaptando às demandas da tecnologia operada.

\section{Conclusões}

Os resultados deste estudo contribuem com a produção de conhecimento na área do design da informação, ao observar sistematicamente a produção imagética d'O Gráfico Amador; assim como produção gráfica, ao testar novas tecnologias na manufatura de matrizes tipográficas e também avaliar qualidade de impressão e resistência de material. Embora ainda existam empresas que manufaturam clichês em fotopolímero e zinco, e peças cortadas em madeira para impressão tipográfica mundo afora; os achados práticos dessa pesquisa podem ser utilizados pelas oficinas tipográficas dos cursos de design destinadas para fins educacionais, assim como as oficinas de fins artísticos e comerciais.

Ao apresentarmos o resultado do teste de impressão com diferentes critérios, esperamos que a escolha do material seja adequada a cada situação particular. Para nós, o linóleo foi o material mais adequado, já que ele se encontrava disponível no laboratório e teve a melhor performance nos quesitos uniformidade, cobertura e ajuste de máquina.

\section{Agradecimento}

Agradecemos à Pró-Reitoria de Pesquisa e Pós-Graduação da UFPE, ao Conselho Nacional de Desenvolvimento Científico e Tecnológico (CNPq), ao Laboratório de Práticas Gráficas (LPG) e ao Grupo de Experimentos em Artefatos 3D (GREA3D) do Departamento de Expressão Gráfica da UFPE. 


\section{Referências}

Lima, Guilherme C. (2014). O gráfico amador: as origens da moderna tipografia brasileira. Rio de Janeiro: Verso Editora.

Neder, Rafael. (2014). A prática contemporânea da impressão tipográfica no design gráfico brasileiro. Tese (Mestrado). São Paulo, Brasil: Universidade Anhembi Morumbi.

Oliveira, Diego Jucá de Lima. (2016). O uso da prototipagem e fabricação digital no ambiente do FAB LAB. Tese (Mestrado). Porto Alegre, Brasil: Universidade Federal do Rio Grande do Sul.

Porta, Frederico. (1958). Dicionário de Artes Gráficas. Porto Alegre: Globo.

\section{Sobre os autores}

Filipe Aca, graduando, UFPE, Brasil <acafilipecosta@gmail.com>.

Isabella Ribeiro Aragão, Doutora, UFPE, Brasil <isabella.aragao@gmail.com>

Raquel Alcantara, graduanda, UFPE, Brasil <raquelmtalcantara@gmail.com>

Silvio Barreto Campello, PhD, UFPE, Brasil <silvio.campello@ufpe.br> 